\title{
Controlling of autoxidation process in biscuits using flavonoids extract from tea (Camellia sinensis)
}

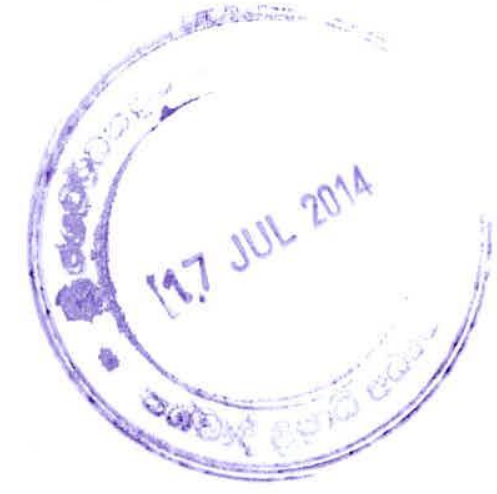

BY

CHARITH C. SENARATNE

DEPARTMENT OF FOOD SCIENCE AND TECHNOLOGY

FACULTY OF APPLIED SCIENCE

UNIVERSITY OF SRI JAYAWARDENAPURA

NUGEGODA

SRI LANKA

2012 
The work described in this thesis was carried by me, under the supervision of Dr.( Mr.) S.B Navaratne and Mr. D.M.V.A Senaratne and the report on this thesis has not been submitted in whole or in part of any university or any other institution for another Degree/ Diploma.

$26 / .01 / 2014$

Date

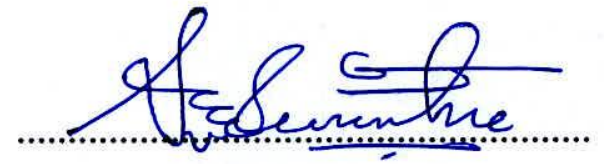

Charith C. Senaratne 


\title{
Controlling of autoxidation process in biscuits using flavonoids extract from tea (Camellia sinensis)
}

\author{
By
}

\section{Charith C. Senaratne}

A Research report Submitted in

Partial Fulfillment of the Requirements of the Advanced Course

In

Food Science and Technology

For Post Graduate Degree of

\section{Master of Science at Faculty of Applied Science}

University of Jayewardenepura,

Gongodawila, Nugegoda

Sri Lanka

2012

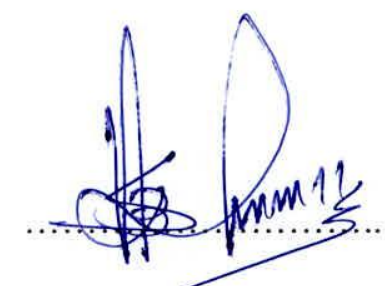

Dr. S.B. Navaratne,

Internal Supervisor,

Dep.of Food Science and Technology,

Faculty of Applied Science,

University of Sri Jayewardenepura,

Sri Lanka.

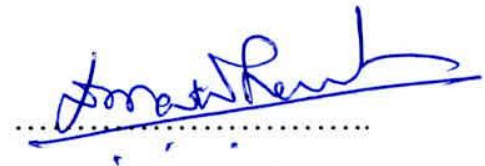

Mr. D.M.A.V Senaratne,

External Supervisor,

General Manager (Group),

Quality Assurance, Research and Development

Ceylon biscuits Limited

Sri Lanka. 


\begin{abstract}
This research study was conducted to determine influence of natural antioxidants extracted from plant based material to suppress autoxidation process of bakery products, specially biscuits. Effectiveness of flavonoids in suppress of autoxidation of shortening agent was monitored interns of change occurrence on chemical properties and organoleptic properties of biscuits as well. Moreover, chemical analysis for 6 treatments pertaining to the peroxide value and free fatty acid level were conducted for biscuits just after manufacturing and after 6 months of storage.

The data were analyzed according to kruskal-wallis non parametric ANOA statistical test method and result revealed that calculated "H-value" were lower than the table $\mathrm{H}$-value with respect to all sensory stimuli. Therefore, sensory analysis review that sensory stimuli of 6 biscuits with control treatment are no significantly difference in just after preparation as well as six month after preparation.

According to this research, there is significant difference ( $L S D \geq 0.3742$ ) between commercial product and treatment C ( $200 \mathrm{ppm}$ flavonoids level of green Tea extract), E (300 ppm flavonoids level of Refuse Tea extract), F (200 ppm flavonoids level of Refuse Tea extract) and G(Control sample). Therein, treatments of $\mathrm{C}, \mathrm{E}, \mathrm{F}$ and $\mathrm{G}$ have low antioxidant properties compare with commercial scale antioxidant. There is NO significant difference (LSD $\leq 0.3742$ ) between commercial biscuits and $\mathrm{A}(400 \mathrm{ppm}$ polyphenol level of green Tea extract), B(300 ppm polyphenol level of green Tea extract) and $\mathrm{D}(400 \mathrm{ppm}$ polyphenol level of Refuse Tea extract). Result of this, treatment A, B and D contain, much similar antioxidant properties compare with commercial scale antioxidant.

There was significant (LSD $\geq 0.07858$ ) difference between 6 treatments on development of FFA values compare with commercial scale biscuits. Even though, all the treatments unable to retard FFA producing ability compare with commercial scale antioxidant. But, they were not exceeding rancid level of $1 \%$ except control. However, all samples were obtained, low FFA value which compare with SLSI recommended level $(1 \%$,). Therefore, flavonoids extract from tea having significant impact from controlling FFA value in biscuits, during the storage period.

All treatments were not impact on sensory stimuli in just after preparation and after the six month storage period. Therefore, manufacture can be able to used, tea flavonoids as antioxidant without influencing the sensory stimuli. According to this research, can be conclude, tea flavonoids can be used as natural antioxidant in biscuits industry.
\end{abstract}




\section{ACKNOLEDGEMENT}

First and foremost I convey my deepest gratitude to my internal supervisor Dr. S.B.Nawaratne, Department of Food Science and Technology, Faculty of Applied Science, University of Jayewardenepura, for his proper guidance, helpful advices, discussion and sparing his valuable time in preparing the project report.

I express my profound gratitude to my external supervisor Mr. D.M.A.V Senaratne, Group Research and Development and Quality Assurance Manager, Ceylon Biscuits Limited, Pannipitiya who guided me successfully, for his kindly help and valuable assistance provide me throughout the study period.

I would like to convey my most sincere appreciation and special thanks, Mrs. Nayana Rathnayaka (R \& D Manager), Mrs. Shanmalie Kumarasiri, Mr. Prabath Chandana and Mr. Maneesha Gamage.( Group R\&D Executives) at Ceylon Biscuits limited, pannipitiya.

It is necessary to remind with gratitude invaluable cooperation rendered by Academic and of non academic staff of the Department of Food Science technology.

I especially grateful to my parents, sister, brothers and brother-in-law for their proper encouragement, inspiration and moral support, sharing and difficulties throughout the research period. I wish to appreciate the help of all my loving friends who encouraged me to complete this research successfully. 


\section{ABBREVIATIONS}

$\begin{array}{ll}{ }^{0} \mathrm{C} & \text { degree of Celsius } \\ \mathrm{g} & \text { gram } \\ \mathrm{HCl} & \text { Hydrochloric acid } \\ \mathrm{L} & \text { Liter } \\ \mathrm{ml} & \text { milliliter } \\ \% & \text { percent } \\ \mathrm{NaOH} & \text { Sodium hydroxide } \\ \mathrm{NaHCO} & \text { Sodium bicarbonate } \\ \mathrm{Hrs} & \text { hours } \\ \mu \mathrm{m} & \text { micrometers } \\ \text { min } & \text { minutes } \\ \text { FFA } & \text { Free fatty acid } \\ \text { KOH } & \text { potassium hydroxide } \\ \text { TPC } & \text { total phenolic content } \\ \text { TFC } & \text { total flavonoids content } \\ \text { GTD } & \\ \text { GMAE } & \\ \text { BTD } & \\ \text { BMAE } & \end{array}$




\section{Contents}

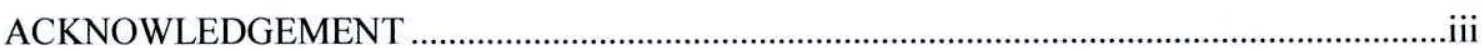

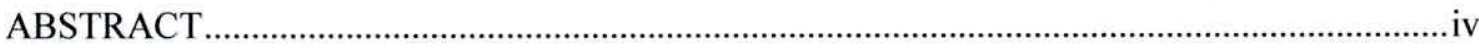

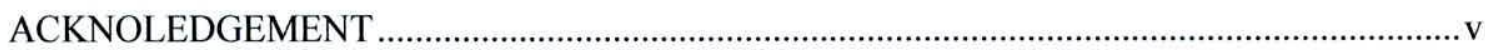

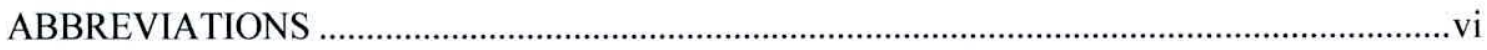

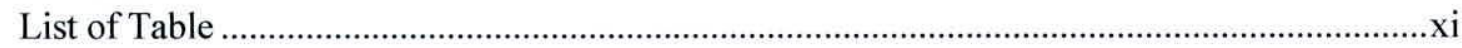

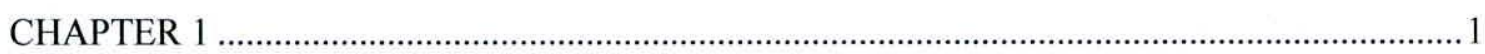

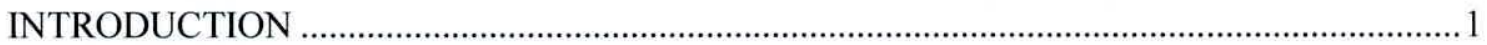

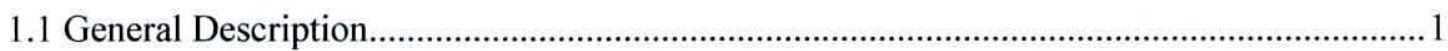

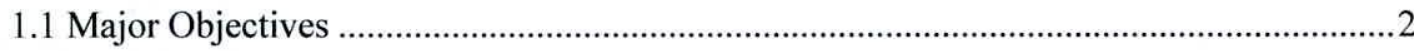

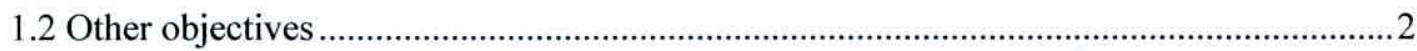

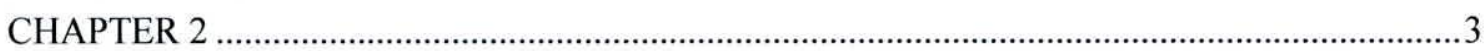

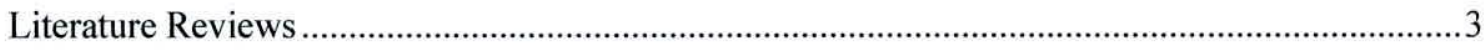

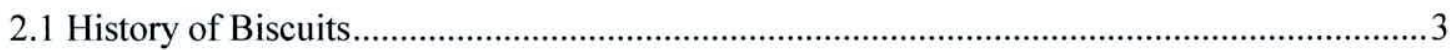

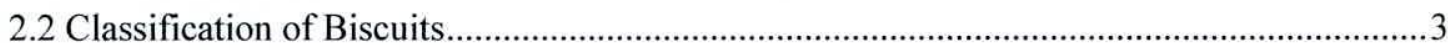

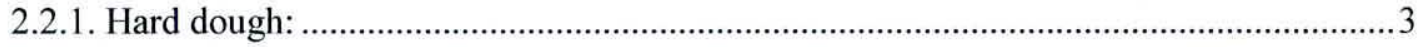

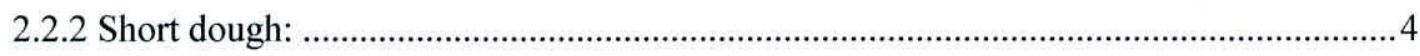

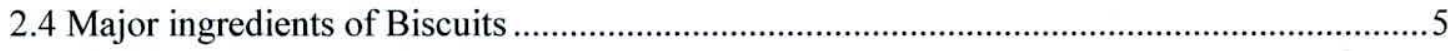

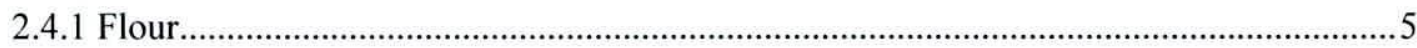

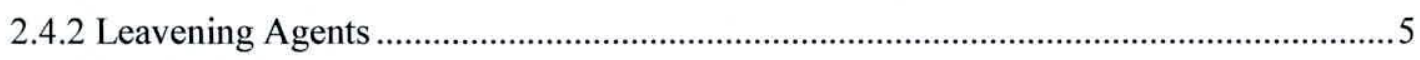

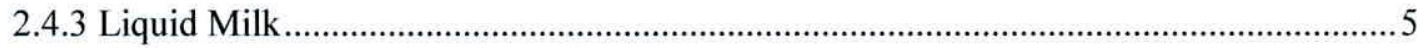

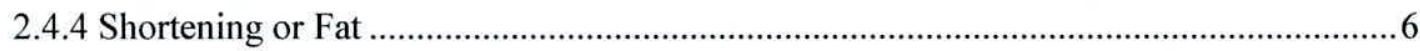

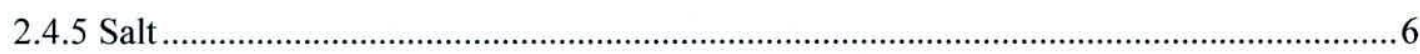

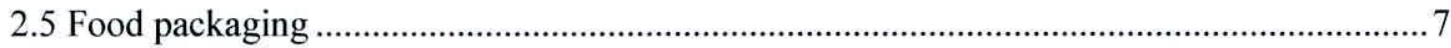

2.5 Important of Antioxidant in bakery Industry ....................................................................

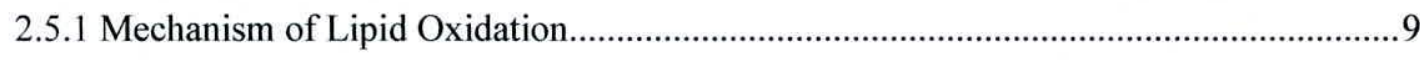

2.6 TPC, TFC and antioxidant activities of tea leaves at different maturity stages .................... 11

2.7 Classification and Mechanism of Antioxidants .................................................................. 11

2.8 Refuse tea produce under black Tea processing .............................................................. 14 
2.9 chemical composition, an overview of Tea

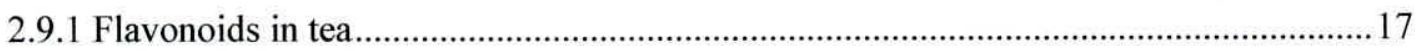

2.9.2 Black Tea Polyphenols ..............................................................................................

2.10 Polyphenols Extraction from Black and Green tea ............................................................. 19

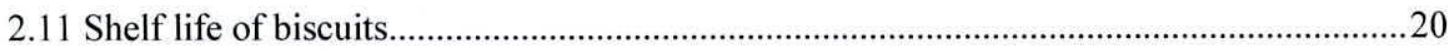

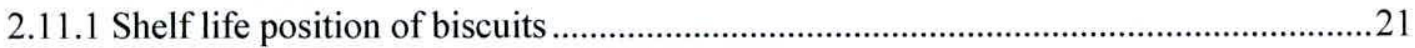

2.12 Factors affecting food packaging interactions and barrier properties ...............................2 21

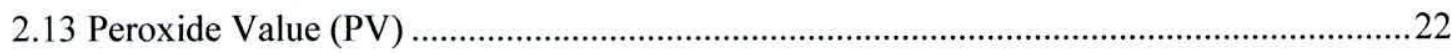

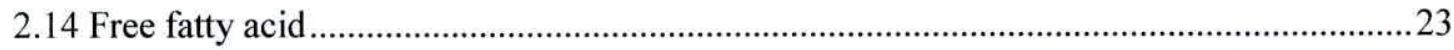

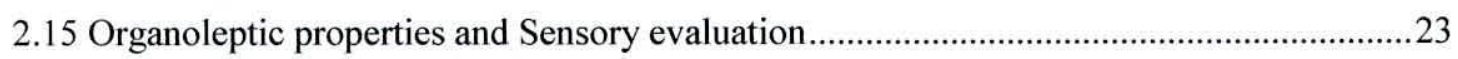

2.15.1 Affective methods/Hedonic methods ……………......................................................24

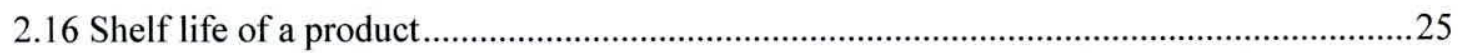

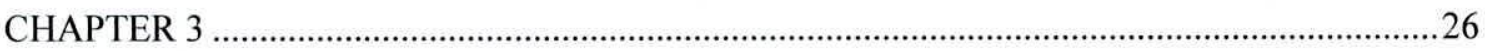

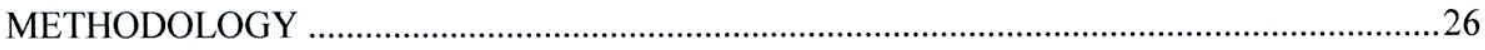

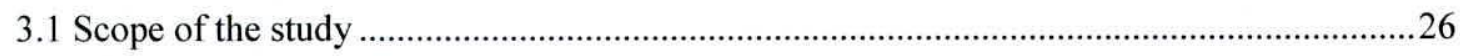

3.2 Extraction of flavanoids from Refuse Tea ………............................................................26

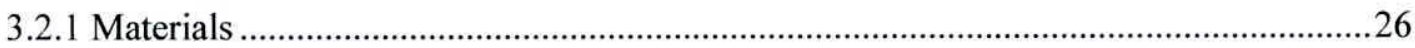

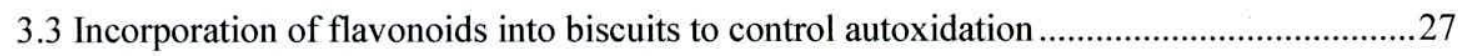

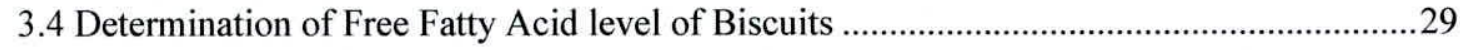

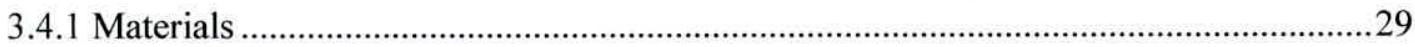

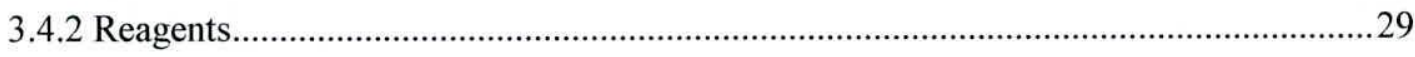

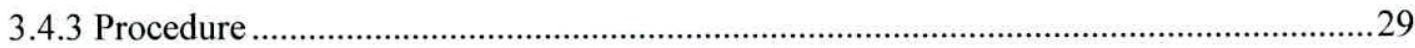

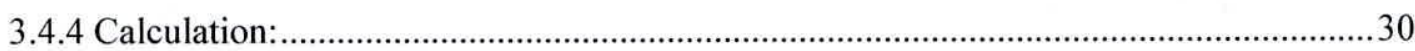

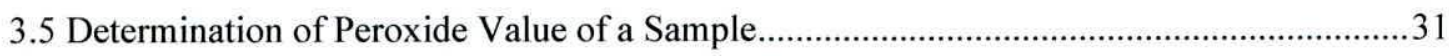

3.6 Evaluation of organoleptic properties of Biscuit......................................................................3

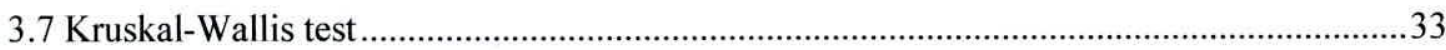

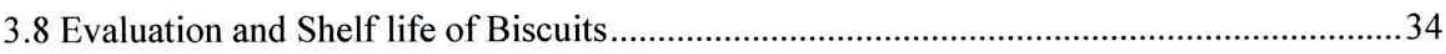

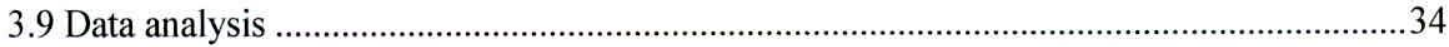




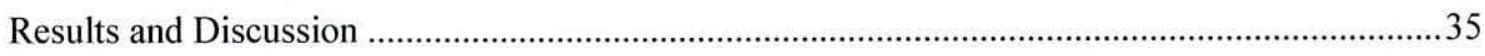

4.1 Evaluations of sensory properties of biscuits along with the control.....................................

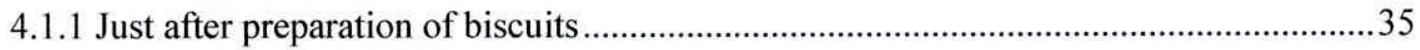

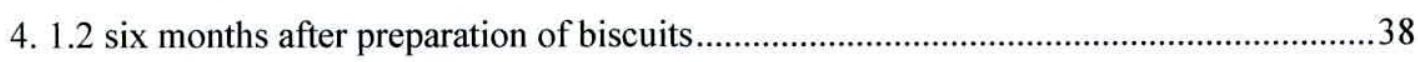

4.2 Peroxide Values of biscuits during six month self life periods .............................................40

4.3 Free Fatty Acid of biscuits during six month self life periods ..............................................4

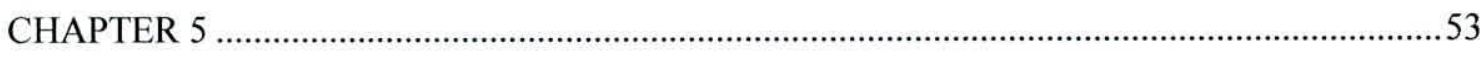

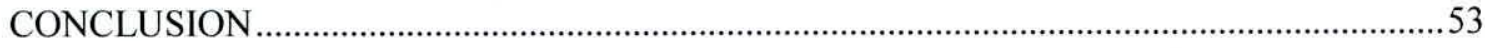

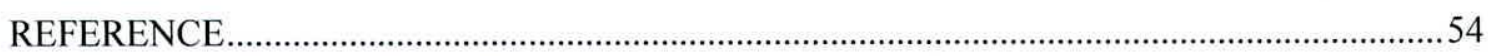

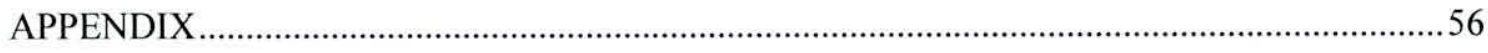

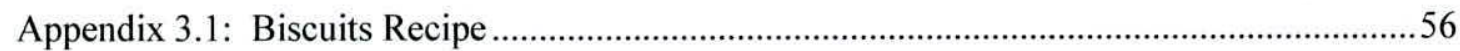

Appendix 3.2 Calculation of Polyphenol amount to be incorporate with biscuits.....................57

Appendix 3.3: Preparation of Standardized Sodium Thiosulphate and Saturated Iodine solution

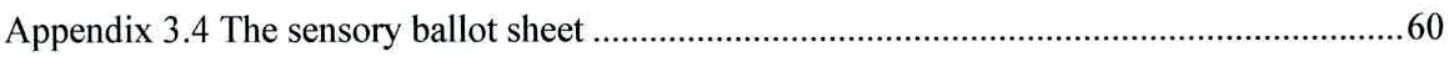

Appendix 4.1 critical value of differences between Rank sum ..................................................61

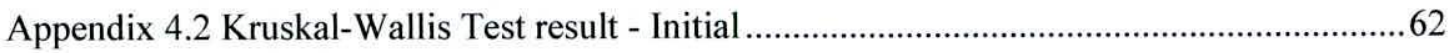

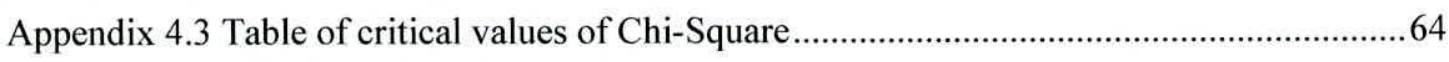

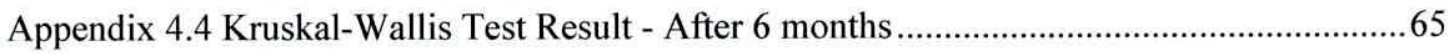

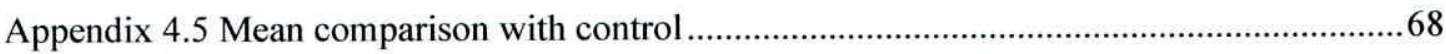

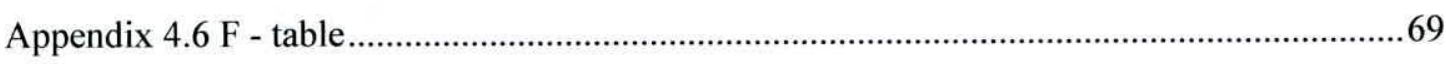

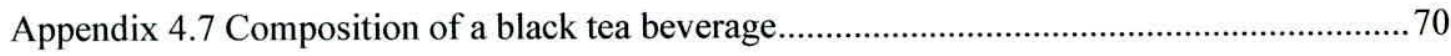




\section{List of Figures}

Figure 2.1: classification of antioxidant (Nanditha, B et al, 2009) ..............................................13

Figure 2.2: Flow chart of black Tea production ……………………………............................... 14

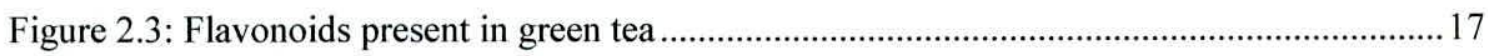

Figure 2.4: Production of Theaflavin and Thearubigin in black tea .............................................. 18

Figure 2.5: Chemical structures of Flavonoids in tea .............................................................. 19

Figure 2.6: The total polyphenolic content (TPC) of tea extract using different extraction methods

Figure 4.1: Mean ranks of Sensory, just after preparation.................................................................37

Figure 4.2: Sensory results (mean ranks) of biscuits, after the six months ..................................39

Figure 4.3: Peroxide value of Green tea extract with control and commercial biscuits .................40

Figure 4.5: Peroxide value of refused tea extract with control and commercial biscuits ..............41

Figure 4.4: Peroxide value of both green tea and refused tea extract with control and commercial

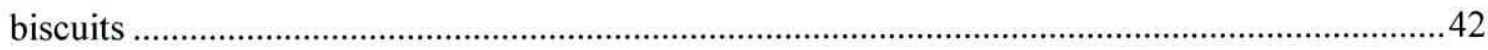

Figure 4.6: FFA value of Green tea extract with control and commercial biscuits ........................44

Figure 4.7: FFA value of Refused tea extract with control and commercial biscuits.....................45

Figure 4.8: FFA value of both Green tea and refused extract with control and commercial

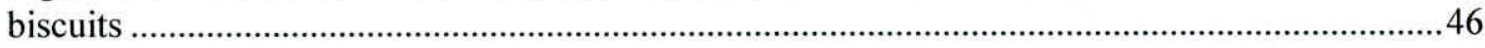

Figure 4.9: Production of theaflavins from epicatechin and epigallocatechin...............................48

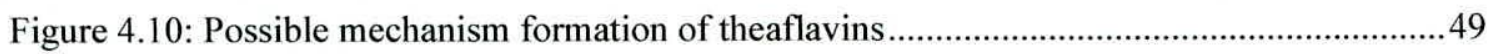

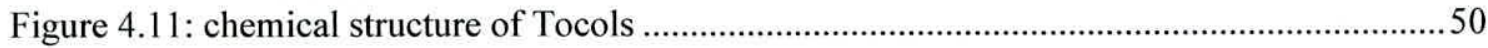

Figure 4.12: Antioxidant activity of quinonoidal systems ......................................................... 51 


\section{List of Table}

Table 2.1: The Composition of a Typical Tea Beverage, \%wt/wt Solids.

Table 2.2 Oxygen transmission rate (OTR in $\mathrm{cm}^{3} \mathrm{~m}^{-2} \mathrm{~d}^{-1} \mathrm{~atm}^{-1}$ at $\left.23{ }^{\circ} \mathrm{C}, 50 \% \mathrm{RH}\right)$ and water vapor transmission rate (WVTR in $\mathrm{g} \mathrm{m}^{-2} \mathrm{~d}^{-1}$ at $23{ }^{\circ} \mathrm{C}, 75 \% \mathrm{RH}$ ) of composite films based on $12 \mu \mathrm{m}$ PET

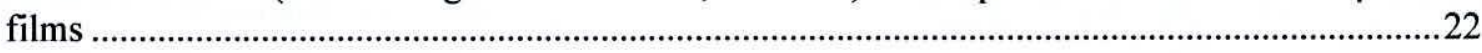

Table 2.3: Classification of test methods in sensory evaluation ......................................................24

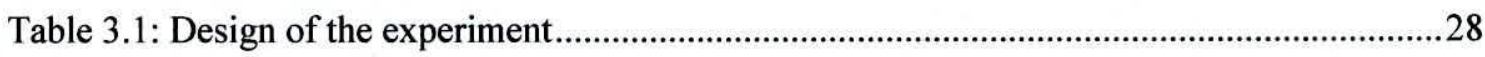

Table 4.1: Ranks sums for 5 sensory stimuli of seven type of biscuits ........................................35

Table 4.2: Ranks sums for 5 sensory stimuli of seven type of biscuits ..........................................38 


\section{CHAPTER 1 \\ INTRODUCTION}

\subsection{General Description}

Biscuits are delicious and expensive food product that usually catering to the upper segment of the social cross profile; is generally made out of soft wheat, sugar, Shortening, leavening agent, water and other essential micro constituents. Since biscuits are a hygroscopic food product, it tends to deteriorate during shelf life; particularly by degradation of fat through the oxidation process. Therefore, the producer must take appropriate precaution to prevent the fat degradation process by incorporation of antioxidants to extend the shelf life of the products. There are three types of antioxidants available in the commercial environment. They are natural antioxidant, nature identical antioxidant and artificial antioxidants.

The antioxidants most frequently used are synthetic phenols such as butylated hydroxy toluene (BHT), butylated hydroxyl anisole (BHA) and propyl gallate. However the safety of these synthetic antioxidants and preservatives has been questioned due to toxicity, liver damage and carcinogenicity. Therefore development and use of safer antioxidants from natural sources are of interested because of possible negative effects of synthetic food additives on human health (Nandhitha. et al). Health consumer tend to purchase food products with natural antioxidant, extracted from plant source such as Tea, Garlic, Spices, tomato ect. Several studies have demonstrated that a variety of plants such as chamomile (Chamomile recutita $\mathrm{L}$ ) cinnamon possess antioxidant and antimicrobial activities (Khaki M. et al, 2012).

Tea (Camellia sinensis) is one of the large plantation sector in sri lanka, contribute to the national coffer 180.4 billion rupees during the year 2013 (Economic and Social statistic of sri lanka 2013) by exporting different form of value added to the global market. Due to glut of tea production there is substantial amount of refuse tea, which just heap and disposed as fertilizer, through it enriched with strong natural antioxidant.

The catechins present in green tea are commonly called polyphenols are a major constituent in the sphere of antioxidant. Green and black teas are processed differently during manufacturing. As far as fresh green tea leaves are Concorde, which are very rich in catechins, because they are not fermented but withered, and catechin oxidation by polyphenol oxidase is prevented by steaming (Japan) or by panning (China) processes thus these polyphenols remain in their 
monomeric forms. The major catechins found in green tea are (-)-epicatechin, (-)epigallocatechin, (-)-epicatechin-3-gallate, and (-)-epigallocatechin- 3-gallate. Whereas in the case of Black tea leaves, which are subjected to crushing and a full fermenting process where catechin derivatives are oxidized, resulting in the formation of the polymeric compounds such as thearubigins and theaflavins. Catechins and other polyphenols have antioxidant activities (Claudia, et al. 2008).

Antioxidants are used as food additives in order to prevent oxidative deterioration of the lipid fraction during storage and processing. The Antioxidants to be used in food products are determined by various factors including legislations, cost and stability. However, when permitted, synthetic antioxidants are widely being used. Because of their low cost and high stability and effectiveness. Their use is specially widespread in oils and fats, destined to subject high temperatures during processing (e.g. frying, baking process). Thus, fat and oil used as ingredients for bakery products are usually stabilized with phenolic antioxidants (Magda, R. et.al).

The keeping quality of baked foods such as crackers, cookies and biscuits is of great economic importance since these products are widely used and are often stored for extended periods before consumption. Therefore, aim of this research is Determination of effectiveness of flavonoids compounds in Refuse and Green teas (Camellia sinensis) for preventing Rancidity as Antioxidants for Biscuits Industry.

\subsection{Major Objectives}

To determine effectiveness of Flavonoids extract from refuse tea and green tea in controlling of fat degradation process in biscuits.

\subsection{Other objectives}

- To monitor the quality changes occurring in biscuits prepared from with and without Natural antioxidant in terms of sensory properties

- To determine peroxide level of biscuits;

- $\quad$ To determine Free fatty Acid level; during 6 month periods of storage. 


\section{CHAPTER 2}

\section{Literature Reviews}

\subsection{History of Biscuits}

The word biscuit comes from the Latin 'bis coctus', which means twice-baked. It is thought that biscuits have been baked for thousands of years and were originally baked in a hot oven and then cooled in a cool oven, although this process would not be found in modern processing factories. Cookie is derived from a Dutch word, koekje, which means little cake. British and European tradition involved serving biscuits in a semiformal situation with tea or coffee in between main meals, specially in the afternoons. Small biscuits were preferred so that a range of appearances and flavours could be offered without a large intake of food.

Biscuits may be regarded as a form of confectionery dried to very low moisture content. Biscuit is defined as a small thin crisp cake made from unleavened dough or production of biscuits as a mixture of flour and water but may contain fat, sugar and other ingredients mixed together into dough which is rested for a period and then passed between rollers to make a sheet.

Biscuits may be classified either by the degree of enrichment and processing or by the method adopted in shaping them. Based on the enrichment criterion, biscuits may be produced from hard dough, soft dough or from batters. The nutritional content however varies with the type of flour used. Soft wheat flour is the suitable flour for biscuit making. This is due to its content of gliadin (a prolamin) and glutamine (glutelin) which under goes hydration in the presence of water, salt and sugar. This protein form a visco-elastic matrix known as gluten, being responsible for the rising nature of dough or permit substantial increase in the volume of baked product of dough and its gas retention capability (Agu, H. O. et al 2007).

\subsection{Classification of Biscuits}

\subsubsection{Hard dough:}

This is similar to bread dough, with a stiff consistency. The gluten network is well developed during mixing, so it is elastic and extensible dough. It is lean dough as the fat and sugar content are low relative to the flour content. Semisweet, unsweetened and savoury biscuits are made from hard dough. 


\subsubsection{Short dough:}

There is clear distinction between short doughs and the hard dought which have lower sugar and fat contents (and therefore more water). Doughs from recipes in short dough are distinguished from hard doughs in that they lack extensibility and elasticity. They readily break when pulled and this is where the term 'short' comes from. A significant amount of fat is usually involved and this is how dough fat comes to be called 'shortening'.

To achieve a tender eating it is important that the mixing of the dough does not allow development of much gluten. This will not happen if there is a lot of fat present (and therefore not much water) but if the fat level is relatively low amount of mixing when flour is in dough should be as little as possible. Over mixing is a common fault and gives harder, tougher and less acceptable biscuits. It is the fats that contribute mostly to a tender eating quality and the effectiveness of the fat in the dough can be increased by using a small quantity of emulsifier. There are many emulsifiers available but commonly used natural Soya lecithin.

During baking it is common for the dough to expand in length and width. They should never shrink, as those of hard dough do, though this may happen if the dough has been over mixed. The expansion, often called 'spread', during baking puts some constrains on the type of baking band (Duncan, M. 2010).

Also, biscuits are classified based on their method of processing, especially they way in which they are shaped, with four main categories:

Sheeting or cutting: This method is used for hard dough, where it is passed through a series of rollers to obtain the desired thickness. The biscuit shapes are cut out of the sheets using a die which may be plastic or metal. The dough needs to be strong and elastic so that the biscuits hold their shape when the scrap is removed from around the cut biscuits.

Rotary moulding: This method is used for short dough and requires dough with a relatively stiff consistency that is not sticky. The dough is compressed into dies mounted on the surface of a roller, with excess dough scrapped off. The moulded dough piece maintains it shape as it is pushed out of the die onto the baking sheet.

Wire cutting: Short dough is extruded through a die and sliced with a tight wire at appropriate intervals. The pressure placed on the dough in the extruder and the thickness of the wire varies dependent on the dough properties. 